\title{
Diurnal tidal variability in the upper mesosphere and lower thermosphere
}

\author{
M. E. Hagan ${ }^{1}$, C. McLandress ${ }^{2}$, J. M. Forbes ${ }^{3}$ \\ ${ }^{1}$ National Center for Atmospheric Research, High Altitude Observatory, Boulder, Colorado, USA \\ ${ }^{2}$ Institute for Space and Terrestrial Science, North York, Ontario, Canada \\ ${ }^{3}$ Department of Aerospace Engineering Sciences, University of Colorado, Boulder, USA
}

\begin{abstract}
We explore tropospheric latent heat release as a source of variability of the diurnal tide in the mesosphere and lower thermosphere (MLT) in two ways. First, we present analyses of the UARS WINDII horizontal wind data, which reveal signatures of nonmigrating tidal effects as large as $25 \mathrm{~m} / \mathrm{s}$ during both vernal equinox and boreal winter. These effects are of greater relative importance during the latter season. Complementary global-scale wave model (GSWM) results which account for a tropospheric latent heat source generally underestimate the observed nonmigrating tidal effects but capture the seasonal variability that is observed. Second, we pursue a new parameterization scheme to investigate seasonal variability of the migrating diurnal tidal component of the latent heat source with GSWM. These results confirm previously reported seasonal trends, but suggest that the MLT effects may be as much as an order of magnitude larger than earlier predictions.
\end{abstract}

\section{Introduction}

Measurements from the Wind Imaging Interferometer (WINDII) and High-Resolution Doppler Interferometer (HRDI) on the Upper-Atmosphere Research Satellite (UARS) have provided a wealth of information on mesosphere and lower thermosphere (MLT) dynamics since UARS was launched some 5 years ago. Despite significant differences in measurement techniques, the HRDI (Hays et al., 1993) and WINDII (Shepherd et al., 1993) horizontal wind measurements are largely consistent (Burrage et al., 1996; Gault et al., 1996). Zonally averaged and diurnal mean data from the two instruments have been recently combined to produce a zonal and meridional wind climatology that extends from 50

Correspondence to: M. E. Hagan to $200 \mathrm{~km}$ (McLandress et al., 1996b). Similarly, two very different data reduction techniques have revealed HRDI and WINDII horizontal wind signatures of the diurnal tide (e.g., Hays et al., 1994; McLandress et al., 1994) which are also comparatively consistent (e.g., Hagan et al., 1995b).

Conversely, pronounced differences emerge when UARS MLT wind measurements are compared with ground-based diagnostics (Burrage et al., 1996). Specifically, both HRDI and WINDII measure wind speeds that are systematically larger than those observed with ground-based MF radars. These same trends affect comparative diurnal tidal diagnostics (e.g., Hagan et al., 1995b). Despite impressive agreement between the phases associated with both ground-based and satelliteborne measurements as well as tidal model predictions, there are disturbing differences in diurnal tidal amplitudes. Some of the more consistent trends that emerge from such investigation can be summarized as follows: (1) the global-scale wave model (GSWM) systematically underestimates HRDI and WINDII diurnal signatures near the location of peak tidal wind amplitude $\left(20^{\circ}\right)$ during equinox (e.g., Burrage et al., 1995), and (2) HRDI and WINDII diurnal tidal amplitudes are systematically larger than those determined from the radar data (e.g., Hagan et al., 1995b). The differences are most pronounced above an altitude of $90 \mathrm{~km}$. Of more significance to our investigation, however, the radar and satellite-measurement tidal differences are relatively larger at all altitudes over Hawaii.

The GSWM underestimate of the seasonal variability of the diurnal tide has been discussed in some detail by Burrage et al. (1995), who noted that this weakness may be largely attributable to the dissipation in the model. Recently, Khattatov et al. (1997) specified monthly tidal dissipation contours by assimilating HRDI data into a linearized tidal model in a series of iterative calculations. When this dissipation replaces the standard formulation in GSWM, there is strong seasonal variability in the resultant tidal fields (Geller et al., 1997). While these results support the major claim of Burrage et al. (1995), 
seasonal variability may be attributable to other effects that have yet to be fully investigated with GSWM. Specifically, (1) the accuracy of specifications of tidal forcing associated with the absorption of infrared and ultraviolet radiation in GSWM, (2) the plausibility of heretofore unidentified sources of migrating tidal components, and (3) the potential effects of nonmigrating tides may also all contribute to the strong seasonal variability of the diurnal tide in the MLT. In this manuscript, we present an interim report on topics (2) and (3).

Hagan (1996) estimated the potential effects of latent heat release associated with cloudiness and rainfall on the migrating semidiurnal tide aloft by including these effects in GSWM using a simple parameterization formulated by Hong and Wang (1980). MLT temperature perturbations of up to $25^{\circ} \mathrm{K}$ resulted and underscored the need to pursue additional investigation of this tidal source. Forbes et al. (1997) report on more recent GSWM calculations and provide still more evidence of pronounced latent heat effects in the MLT. Using a newly developed tidal forcing scheme derived from a 7year 3-h average cloud imagery database, they report migrating MLT wind signatures of $10-20 \mathrm{~m} / \mathrm{s}$ in response to both the diurnal and semidiurnal components of the annual average latent heat excitation.

The results reported by Forbes et al. (1997) are an order of magnitude stronger than the GSWM migrating tidal signatures calculated with latent heat forcing of Williams and Avery (1996): Hagan et al. (1997). Notably, the Williams and Avery (1996) scheme was developed using the identical technique employed by Forbes et al. (1997), but for a 1-year cloud imagery database. The remarkable differences in the respective GSWM calculations are solely attributable to these independent latent heat forcing functions and suggest that there may be strong interannual variability associated with latent heat release.

Hagan et al. (1997) also investigated the effects of the nonmigrating diurnal components of latent heat release on MLT wind signatures using the DCA forcing scheme of Williams and Avery (1996). They concluded that, while the effect of a single component was of arguable importance, the collective response of the nonmigrating diurnal tide could appreciably modulate migrating signatures in the MLT particularly during boreal (i.e., northern-hemisphere) winter.

Khattatov et al. (1996) analyzed HRDI data to provide observational evidence of nonmigrating tidal effects in the MLT. They reported longitudinal variability associated with hourly zonal wind averages from a limited data set (January-March 1992) which approached 50 and $30 \mathrm{~m} / \mathrm{s}$ at $20^{\circ} \mathrm{S}$ and $40^{\circ} \mathrm{S}$, respectively. McLandress and Ward (1994) conducted an investigation of tidal and gravity-wave interactions with a middleatmosphere model. Their results identified localized gravity-wave drag as another plausible source of nonmigrating tidal components.

In this report, we present further evidence of nonmigrating diurnal tidal effects found in WINDII data and conduct a quantitative comparison between those and the GSWM diagnostics reported by Hagan et al. (1997). We pay particular attention to the seasonal variability of the modelled and measured nonmigrating tidal effects. We also explore the seasonal variability of the migrating diurnal tide associated with latent heat release using the new forcing functions described by Forbes et al. (1997).

In the following section we present a brief overview of GSWM. Thereafter, we describe the WINDII data and analysis technique employed in this investigation. Subsequently, we contrast our observational nonmigrating diurnal tidal diagnostics with previous numerical estimates. We then highlight the seasonal variability of latent heat effects on the migrating diurnal component. We also discuss the comparative importance of the latent heat source in the MLT as a function of season.

\section{GSWM overview}

As previously discussed, we employ GSWM to carry out the calculations illustrated herein. Hagan et al. (1995a) described the two-dimensional, linearized, steady-state numerical tidal model known as the global-scale wave model (GSWM). Briefly, GSWM solves the extended Navier-Stokes equations for a specified wavenumber $(s)$ and period $(\omega)$ using a finite difference algorithm (Lindzen and Kuo, 1969). Zonal, meridional, and vertical wind components as well as temperature perturbations are resolved as a function of latitude $\left(87^{\circ} \mathrm{S}\right.$ to $\left.87^{\circ} \mathrm{N}\right)$ and altitude from the ground into the thermosphere. We exclude the thermospheric tidal source due to in situ absorption of extreme ultraviolet radiation from our current calculations, so here we only report GSWM results up to $125 \mathrm{~km}$. Nevertheless, we set the GSWM upper boundary at $250 \mathrm{~km}$ for the calculations reported herein, so as to avoid contamination of our solutions associated with reflection of the tidal wave at the upper boundary.

The GSWM background atmosphere is specified by a series of empirical models. Zonal mean temperature and density fields come from the MSISE90 empirical model (Hedin, 1991). Between $\sim 20$ and $80 \mathrm{~km}$ the GSWM background winds are calculated from the MSISE90 zonal mean pressure gradients assuming geostrophic balance. Below that region the semiempirical model of Groves $(1985,1987)$ is used, while zonal mean winds between $\sim 80$ and $110 \mathrm{~km}$ are specified by the empirical model of Portnyagin and Solov'eva (1992a, b).

GSWM migrating tidal forcing is discussed in detail by Hagan (1996). Briefly, GSWM employs Groves' (1982) formulae for tropospheric tidal forcing due to isolation absorption by water vapor. Groves used global models of specific humidity, $q$, based upon 3-month averages of data centered on January, April, July, and October to calculate heating rates for the major diurnal and semidiurnal tidal modes. GSWM tidal heating in the stratosphere and throughout the mesosphere into the lower thermosphere is based upon a parameterization reported by Strobel (1978). CIRA O 3 (Keating et al., 1990) and MSISE90 $\mathrm{O}_{2}$ (Hedin, 1991) densities are utilized to calculate hourly heating rates at each 
latitude and altitude and for every month of the year. Once hourly heating rates are calculated, diurnal mean and harmonic components are determined via Fourier decomposition. These calculations result in monthly GSWM stratospheric and lower mesospheric tidal forcing functions which vary with latitude and altitude.

GSWM nonmigrating tidal forcing is detailed by Hagan et al. (1997). Two tropospheric sources have been parameterized; one attributable to latent heat release associated with deep convective activity (DCA), and the other accounts for longitudinal variability in insolation absorption of tropospheric water vapor. In the case of the latter, GSWM invokes the nonmigrating components of Groves' (1982) formulae. A scheme based on global cloud imagery (Williams and Avery, 1996) is used to account for DCA effects in GSWM.

Tidal dissipation in the GSWM includes a scheme to account for the effects of gravity-wave drag on the diurnal tide (after Miyahara and Forbes, 1991) and latitude and seasonally dependent eddy diffusivity (after Garcia and Solomon, 1985). We refer the reader to Hagan et al. (1993, 1995a, 1997), Hagan (1996), and references therein for additional details regarding the GSWM.

\section{Diurnal tidal variability due to nonmigrating sources}

\subsection{Observational evidence}

Winds from WINDII on UARS have provided invaluable information about solar tides in the lower and middle thermosphere (McLandress et al., 1994, 1996a). Of particular importance to the present study is the result that the propagating diurnal tide exhibits a strong semiannual variation in amplitude in the lower thermosphere, with equinoctial maxima and solstitial minima. Since zonal averaging was used to extract the tidal signatures, these studies dealt only with the migrating component of the diurnal tide. To examine longitudinal variations that would arise from a combination of migrating and nonmigrating diurnal tidal components, the data was averaged again, but over $90^{\circ}$ longitudinal sectors rather than over the full latitude circle. Since UARS orbits the earth 15 times per day, a maximum of four crossings of each latitude in each longitude bin (at approximately the same local time) is possible. In order to remove spatial bins with isolated data points, the longitudinal averaging was performed only in bins containing at least three measurements. Aside from these differences the analysis was identical to that of McLandress et al. (1996a) (henceforth MSS96): each day of data was first separated into ascending and descending orbits, binned in $5^{\circ}$ latitude intervals and averaged over each longitude sector. The resulting averaged daily data sets were then combined by binning in 1-h local solar time intervals. As in MSS96, only winds from the $\mathrm{O}(1 \mathrm{~S})$ "green-line" emission were used (Gault et al., 1996). Because WINDII's standard observing sequence provides daytime green-line observations four times per week and nighttime measure- ments twice per week, several months of data are required to provide adequate local-time coverage to extract the diurnal tide. Moreover, since this study addresses the seasonal variability of the diurnal tide, only data from the equinox periods (March and April 1992/1993) and solstice periods (December 1992/1993 and January 1993/1994) - the times of the migrating tidal amplitude extrema - were used.

The resulting amplitude and phase of the northward wind component in the four longitudinal sectors for equinox are shown in Fig. 1 for altitudes between 90 and $108 \mathrm{~km}$. (The reader is referred to Fig. 16a of MSS96 for the corresponding migrating tide obtained by averaging over the full $360^{\circ}$.) Although the tidal phase is quite similar in each of the four sectors, there is considerable variation in amplitude. Between $135^{\circ} \mathrm{E}$ and $135^{\circ} \mathrm{W}$ (the Pacific sector) the amplitudes are weakest. There the maximum diurnal winds speeds are some $10-15 \mathrm{~m} / \mathrm{s}$ weaker than the zonal mean results which peak in excess of $60 \mathrm{~m} / \mathrm{s}$ near $94 \mathrm{~km}$ and $20^{\circ}$ latitude (Fig. 16a of MSS96). The results between $45^{\circ} \mathrm{E}$ and $135^{\circ} \mathrm{E}$ (the European/Asian sector) are very similar to Fig. 16a of MSS96, however. In the southern hemisphere the maximum meridional amplitudes between $135^{\circ} \mathrm{W}$ and $45^{\circ} \mathrm{W}$ (the American sector) illustrated in Fig. 1 are $15 \mathrm{~m} / \mathrm{s}$ stronger than peak MSS96 zonal mean values. The same is true between $45^{\circ} \mathrm{W}$ and $45^{\circ} \mathrm{E}$ (the Atlantic sector), but for northern-hemisphere results. Some of these same features are observed in similar results for the eastward wind component (not shown). Notably, the zonal amplitude is also comparatively weakest in the Pacific sector.

The meridional results for solstice are shown in Fig. 2. (These can be compared to the migrating component results illustrated in Fig. 17a of MSS96.) As in the equinoctial case (Fig. 1) the amplitude of the meridional wind component shows considerable longitudinal variation with the weakest signatures occurring in the Pacific sector $\left(135^{\circ} \mathrm{E}-135^{\circ} \mathrm{W}\right)$. Unlike equinox, the solstice results in the European/Asian sector $\left(45^{\circ} \mathrm{E}\right.$ and $135^{\circ} \mathrm{E}$ ) are no longer representative of the migrating tide (Fig. 17a of MSS96). Rather, northern-hemisphere amplitudes over Europe and Asia exceed maximum MSS96 results by $20-25 \mathrm{~m} / \mathrm{s}$ near $20^{\circ} \mathrm{N}$ and $95 \mathrm{~km}$. There are also comparative seasonal differences in the American sector $\left(135^{\circ} \mathrm{W}\right.$ and $\left.45^{\circ} \mathrm{W}\right)$, since southern hemisphere results do not exceed the MSS96 amplitudes during December/January. Finally, it is the Atlantic-sector $\left(45^{\circ} \mathrm{W}\right.$ and $\left.45^{\circ} \mathrm{E}\right)$ results which are comparatively larger than the MSS96 migrating tide (Fig. 17a of MSS96) in both the summer and winter hemispheres. The zonal wind component results for solstice (not shown) also differ in detail with the complementary results for equinox. Once again, the zonal wind amplitudes observed by WINDII are weakest in the Pacific sector during solstice.

Comparison of Figs. 1 and 2 suggests that the observed longitudinal asymmetries in the diurnal tide are of greater relative importance at solstice than at equinox, but that seasonal trends differ in detail with longitudinal sector and altitude. The relative importance of the nonmigrating effects are further quantified in 

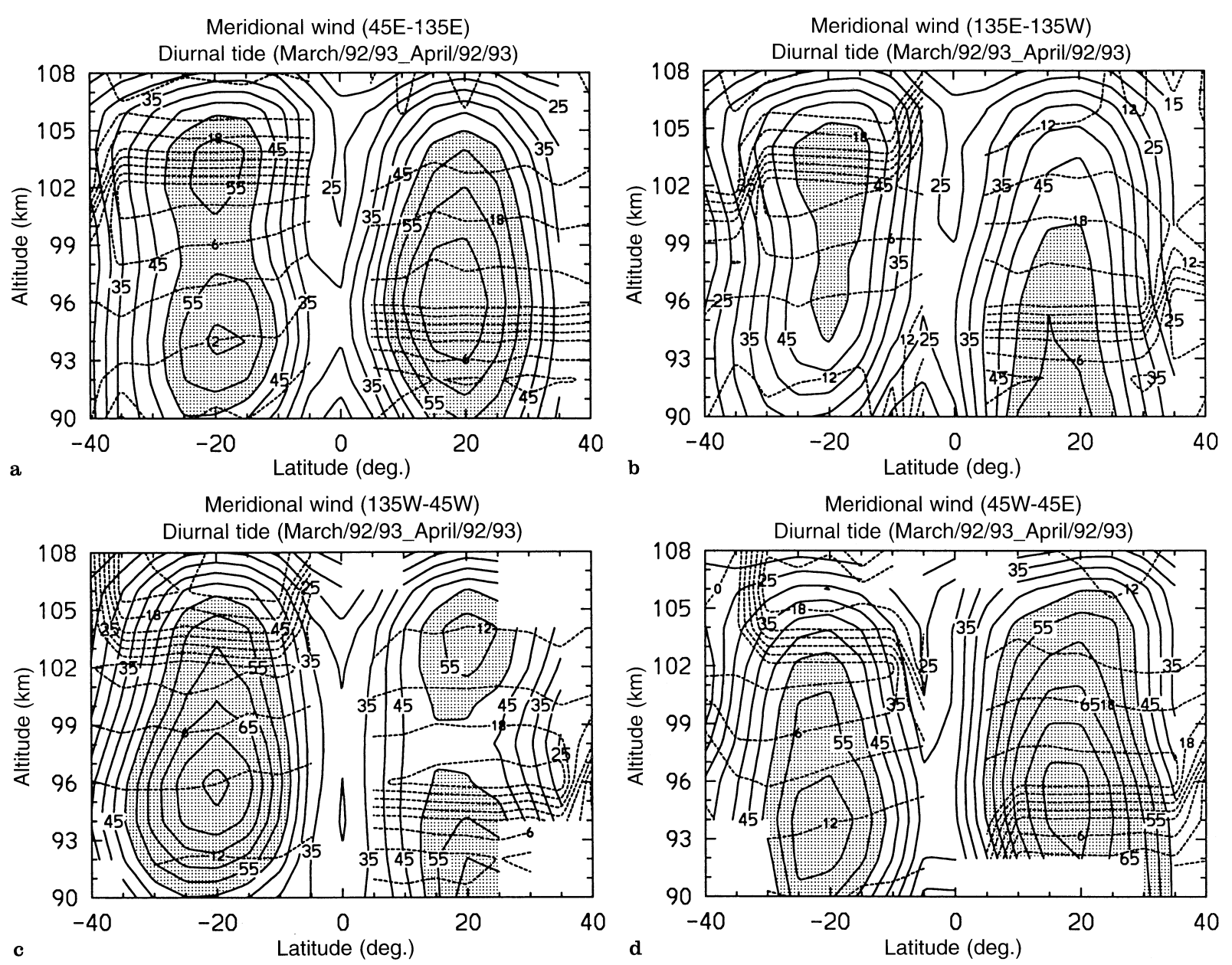

Fig. 1. Contours of meridional wind amplitude (solid lines) and phase (dashed lines) of the diurnal tide observed by WINDII for March/ April 1992 and 1993 at a $45^{\circ} \mathrm{E}$ to $135^{\circ} \mathrm{E}, \mathbf{b} 135^{\circ} \mathrm{E}$ to $135^{\circ} \mathrm{W}$, c $135^{\circ} \mathrm{W}$

to $45^{\circ} \mathrm{W}$, and $\mathbf{d} 45^{\circ} \mathrm{W}$ to $45^{\circ} \mathrm{E}$ longitude sectors. Amplitude contours $>50 \mathrm{~m} / \mathrm{s}$ are shaded. The phase (local time of maximum) is contoured using a 3 -h interval

Table 1, which presents both the northward and eastward diurnal wind amplitudes and phases observed by WINDII at $20^{\circ}$ and $96 \mathrm{~km}$ for each season and longitude sector. Table 1 also includes the zonal average diurnal tidal results reported by MSS96. The meridional wind amplitude at $20^{\circ} \mathrm{N}$ between $135^{\circ} \mathrm{E}$ and $135^{\circ} \mathrm{W}$ is $36 \mathrm{~m} / \mathrm{s}$ during solstice and $59 \mathrm{~m} / \mathrm{s}$ during equinox. These amplitudes are $54 \%$ and $69 \%$ of the maximum northward amplitude observed at $20^{\circ} \mathrm{N}$ and $96 \mathrm{~km}$ during respective seasons, providing further evidence that non-migrating tidal effects are comparatively more important during solstice. While the cited amplitudes do not represent the minimum values at this location, the comparative suppression of the migrating response in the Pacific sector is undoubtedly the most persistent feature of the observed nonmigrating tidal effects during both seasons. In the following section we investigate similar trends in GSWM in order to interpret these results.

\subsection{The MLT response modelled by GSWM}

As previously mentioned, Hagan et al. (1997) recently investigated the MLT response to two tropospheric

nonmigrating diurnal tidal sources: (1) latent heat release using a scheme based on DCA data (Williams and Avery, 1996), and (2) zonally varying infrared radiation (IR) absorption due to longitudinal variations in tropospheric water vapor (Groves, 1982). They concluded that GSWM migrating northward climatologial signatures (after Hagan et al., 1985a) were modulated by the collectively effects of several diurnal tidal components; namely the stationary oscillation and the westward-propagating zonal wavenumber 1,2 , and 5 components attributable to DCA along with the stationary oscillation associated with IR. The GSWM migrating zonal wind was also significantly modulated by most of the aforementioned components of the nonmigrating diurnal tide, except this field was affected by the eastward-propagating zonal wavenumber 3 rather than the westward-propagating zonal wavenumber 5 DCA source. Further, Hagan et al. (1997) reported that these nonmigrating tidal effects were strongest during boreal winter.

Herein, we use the same model results discussed by Hagan et al. (1997) to calculated the collective GSWM migrating and nonmigrating MLT response at the central longitude of each sector used in the WINDII analysis. 

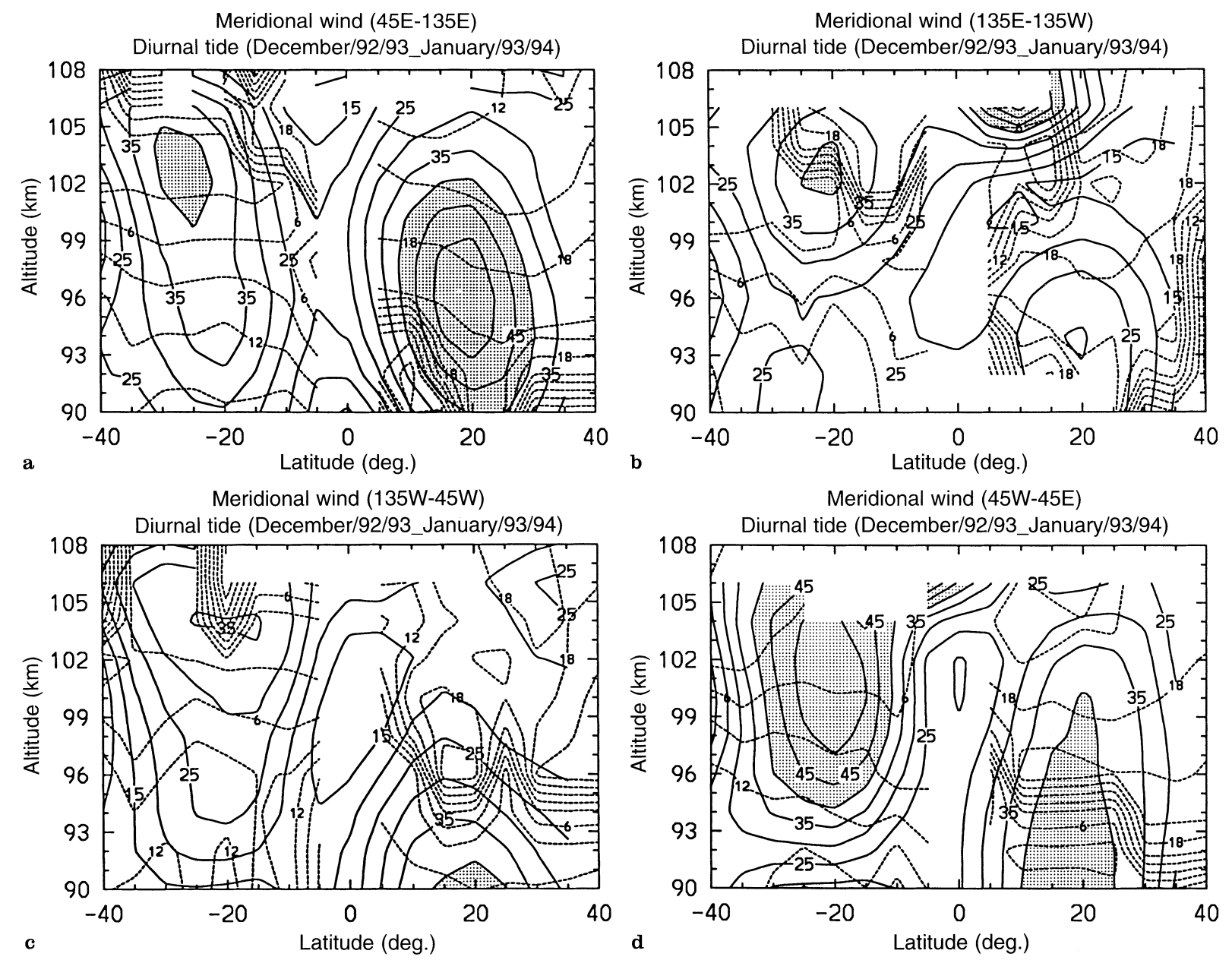

Fig. 2a-d. Contours of meridional wind amplitude (solid lines) and phase (dashed lines) of the diurnal tide observed by WINDII for December 1992, 1993 and January 1993, 1994 at: a $45^{\circ} \mathrm{E}$ to $135^{\circ} \mathrm{E}, \mathbf{b}$

$135^{\circ} \mathrm{E}$ to $135^{\circ} \mathrm{W}$, c $135^{\circ} \mathrm{W}$ to $45^{\circ} \mathrm{W}$, and $\mathbf{d} 45^{\circ} \mathrm{W}$ to $45^{\circ} \mathrm{E}$ longitude sectors. Amplitude contours $>40 \mathrm{~m} / \mathrm{s}$ are shaded. The phase (local time of maximum) is contoured using a 3 -h interval

Table 1. Nonmigrating signatures of the diurnal tide at $96 \mathrm{~km}$ observed by WINDII

\begin{tabular}{|c|c|c|c|c|}
\hline \multirow{8}{*}{$\begin{array}{l}45^{\circ} \mathrm{E}-135^{\circ} \mathrm{E} \\
135^{\circ} \mathrm{E}-135^{\circ} \mathrm{W} \\
135^{\circ} \mathrm{W}-45^{\circ} \mathrm{W} \\
45^{\circ} \mathrm{W}-45^{\circ} \mathrm{E} \\
\text { full } 360^{\circ}\end{array}$} & \multicolumn{4}{|c|}{ Zonal wind perturbations $(\mathrm{m} / \mathrm{s} /$ local solar $\mathrm{h}$} \\
\hline & \multicolumn{2}{|l|}{ equinox } & \multicolumn{2}{|l|}{ solstice } \\
\hline & $20^{\circ} \mathrm{N}$ & $20^{\circ} \mathrm{S}$ & $20^{\circ} \mathrm{N}$ & $20^{\circ} \mathrm{S}$ \\
\hline & $37.2 / 5.1$ & $37.8 / 3.3$ & $36.4 / 2.0$ & $33.7 / 6.1$ \\
\hline & $24.2 / 4.4$ & $24.3 / 2.9$ & $21.8 / 2.7$ & $19.7 / 1.2$ \\
\hline & $35.7 / 3.4$ & $40.1 / 2.5$ & $27.5 / 4.7$ & $20.5 / 6.7$ \\
\hline & $32.4 / 4.8$ & $41.6 / 4.3$ & $39.5 / 3.2$ & $34.7 / 5.5$ \\
\hline & $30.6 / 4.3$ & $33.6 / 3.3$ & $31.9 / 3.3$ & $25.4 / 5.0$ \\
\hline & \multicolumn{4}{|c|}{ Meridional wind perturbations $(\mathrm{m} / \mathrm{s} /$ local $\mathrm{h})$} \\
\hline & \multicolumn{2}{|l|}{ equinox } & \multicolumn{2}{|l|}{ solstice } \\
\hline & $20^{\circ} \mathrm{N}$ & $20^{\circ} \mathrm{S}$ & $20^{\circ} \mathrm{N}$ & $20^{\circ} \mathrm{S}$ \\
\hline $45^{\circ} \mathrm{E}-135^{\circ} \mathrm{E}$ & $77.0 / 22.7$ & $64.4 / 10.3$ & $67.3 / 19.4$ & $44.0 / 10.8$ \\
\hline $135^{\circ} \mathrm{E}-135^{\circ} \mathrm{W}$ & $59.1 / 22.9$ & $63.9 / 9.3$ & $36.3 / 18.7$ & $17.1 / 8.8$ \\
\hline $135^{\circ} \mathrm{W}-45^{\circ} \mathrm{W}$ & $50.2 / 22.8$ & $88.4 / 9.0$ & $34.5 / 22.3$ & $26.6 / 10.3$ \\
\hline $45^{\circ} \mathrm{W}-45^{\circ} \mathrm{E}$ & $87.4 / 22.7$ & $66.2 / 10.0$ & $40.3 / 22.2$ & $52.4 / 10.0$ \\
\hline full $360^{\circ}$ & $69.7 / 22.7$ & $69.0 / 9.5$ & $40.3 / 20.6$ & $35.6 / 10.0$ \\
\hline
\end{tabular}

Results for the meridional component during April and January are illustrated in Figs. 3 and 4, respectively. Several differences between the modelled and measured results (Figs. 1 and 2) are immediately apparent. First, GSWM tidal amplitudes generally peak $10-15 \mathrm{~km}$ higher than WINDII results. Second, the GSWM significantly understimates the peak meridional wind amplitude observed by WINDII during April. This GSWM weakness has been previously noted, as discussed earlier in this report. However, the GSWM meridional wind response at $180^{\circ} \mathrm{E}$ in the center of the Pacific sector is comparatively weaker than the other GSWM results. The only exception occurs above (below) about $104 \mathrm{~km}$ in the northern (southern) hemisphere during January when the meridional wind at $90^{\circ} \mathrm{W}$ is slightly $(<5 \mathrm{~m} / \mathrm{s})$ smaller than what is calculated for $180^{\circ} \mathrm{E}$. The general relative suppression of the diurnal tide is also seen in the GSWM zonal wind fields (not illustrated) with the notably weak American-sector response too. Table 2 further quantifies both the meridional and zonal wind nonmigrating effects as modelled by GSWM at $95 \mathrm{~km}$. 

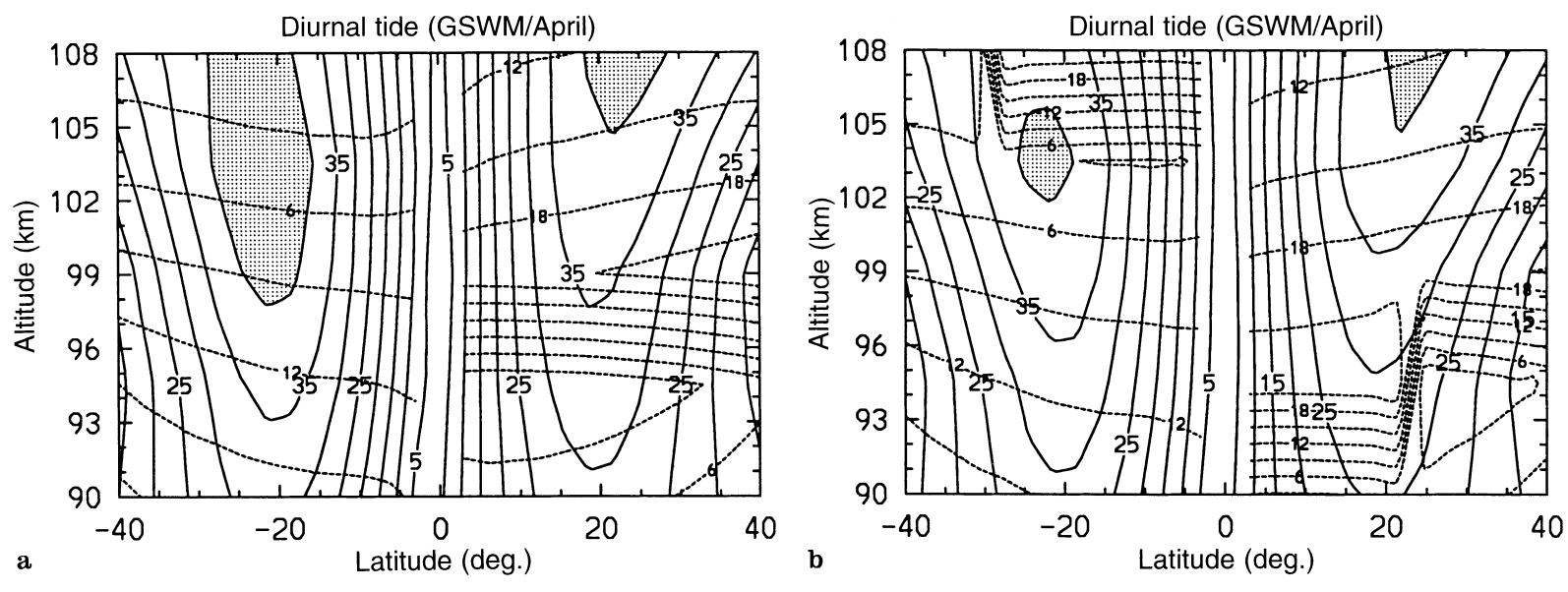

Meridional wind (90W)
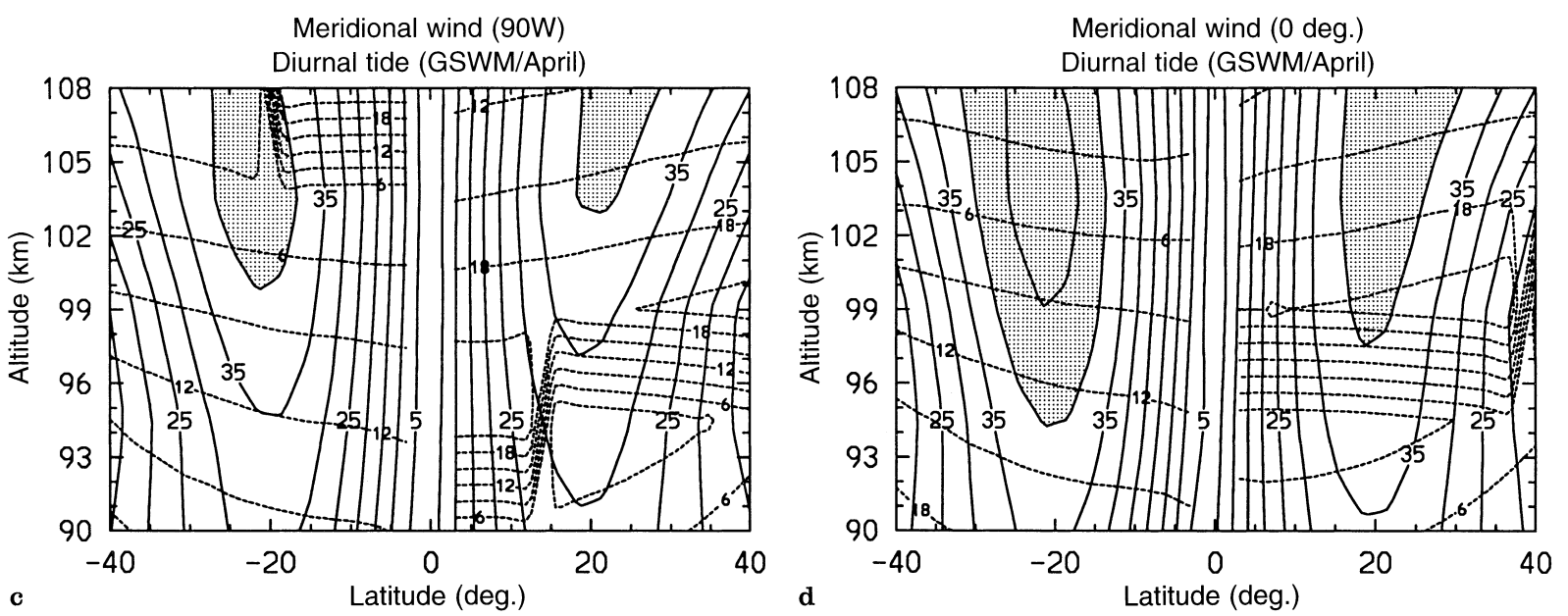

Fig. 3a-b. Contours of meridional wind amplitude (solid lines) and phase (dashed lines) of the diurnal tide modelled by GSWM for April conditions at: a $90^{\circ} \mathrm{E}, \mathbf{b} 180^{\circ} \mathrm{E}, \mathbf{c} 90^{\circ} \mathrm{W}, \mathbf{d} 0^{\circ}$ longitude. Amplitude

contours $>40 \mathrm{~m} / \mathrm{s}$ are shaded. The phase (local time of maximum) is contoured using a 3 -h interval

The longitudinal variability of the diurnal tide observed by WINDII (Figs. 1 and 2) supports the initial claims of Hagan et al. (1997). That is, tropospheric nonmigrating tidal sources affect tidal signatures in the MLT, and these effects are most pronounced during boreal winter. Further, both the observations and the GSWM suggest that the nonmigrating diurnal tide adds to the migrating MLT response in some longitude sectors while subtracting from it in others. Although the observational and numerical results differ in detail, both components of the horizontal diurnal tidal wind are, for the most part, comparatively smaller in the Pacific sector.

\section{Seasonal variability of the migrating diurnal tide due to latent heat release}

In this section we report on GSWM calculations which were designed to investigate whether tropospheric latent heating is an important source of seasonal diurnal tidal variability observed in the MLT (e.g., Figs. 16 and 17 in MSS96). The calculations reported herein are motivated in large part by the pronounced MLT response of the migrating diurnal tide to annual average latent heat forcing described by Forbes et al. (1997). In the following paragraphs we discuss new 7-year-average monthly mean latent heating rates and highlight the resultant GSWM calculations.

Monthly mean diurnal latent heating rates were determined from satellite-based cloud brightness temperature measurements made between 1988 and 1994 using a technique detailed by Forbes et al. 1997). Briefly, cloud brightness temperatures were converted to rainfall rates (Janowiak et al. 1994) and subsequently binned into 3 -h and $2.5^{\circ}$ latitude by $2.5^{\circ}$ longitude bins for each month of the year. Thereafter, a space-time decomposition was performed on these data to obtain the diurnal and semidiurnal components of monthly mean rainfall rates at zonal wavenumbers which ranged from -12 to 12. The migrating diurnal (westward-propagating zonal wavenumber 1) component which results from this analysis is illustrated in Fig 5. These data form the basis for the latitudinal distribution of the monthly mean latent heating rates in GSWM, since we adopt a separable form given by:

$J(z, \theta)=J_{z}(z) J_{\theta}(\theta)$,

where $J$ represents latent heating rate, $z$ is altitude, and $\theta$ is latitude. Therefore, Fig. 5 illustrates the monthly 

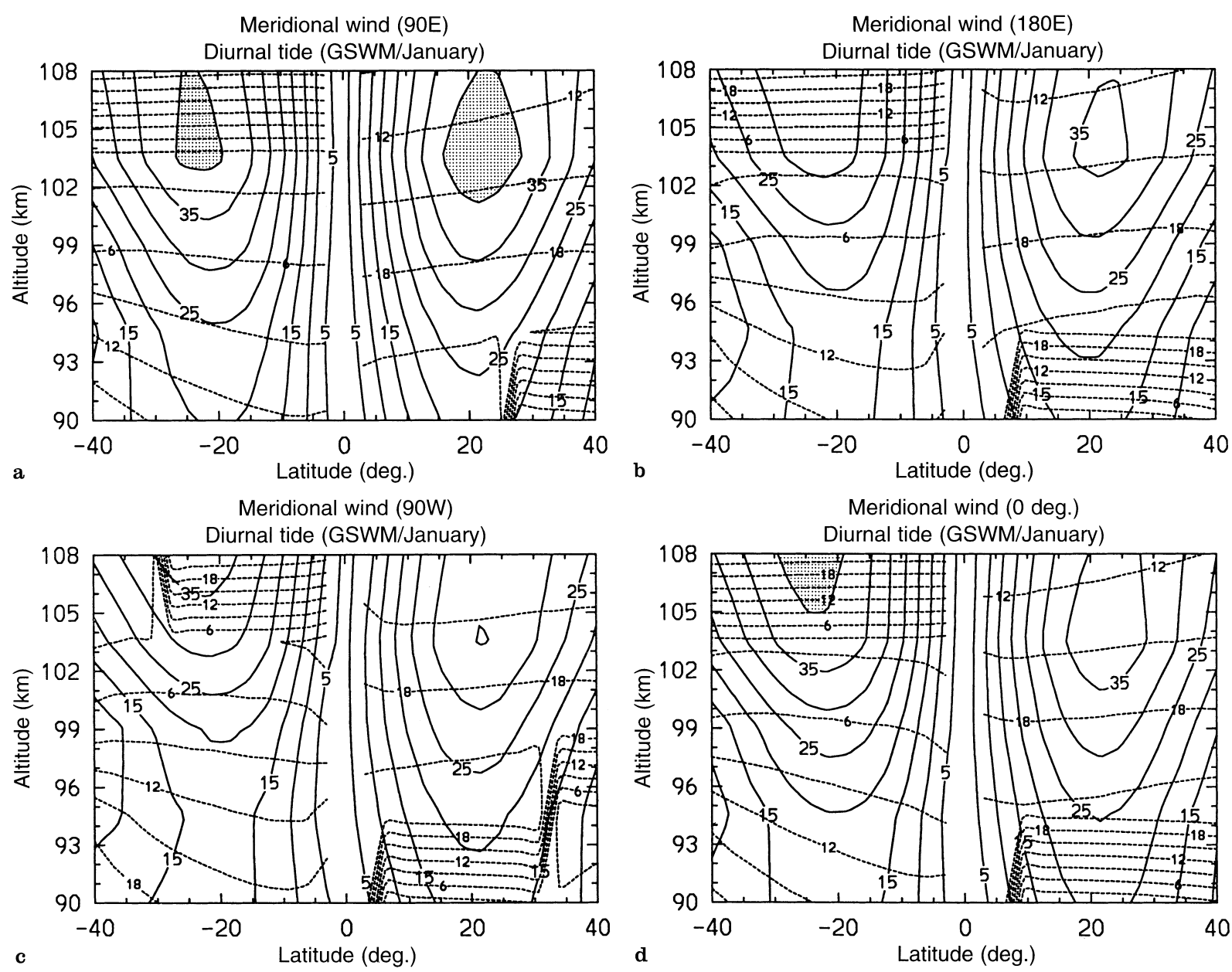

Fig. 4. Same as Fig. 3, except for January conditions

Table 2. Nonmigrating signatures of the diurnal tide at $95 \mathrm{~km}$ modelled by GSWM

\begin{tabular}{|c|c|c|c|c|}
\hline \multirow{8}{*}{$\begin{array}{l}90 \mathrm{E} \\
180^{\circ} \mathrm{E} \\
90^{\circ} \mathrm{W} \\
0^{\circ} \\
\text { Migrating only }\end{array}$} & \multicolumn{4}{|c|}{ Zonal wind perturbations $(\mathrm{m} / \mathrm{s} /$ local solar $\mathrm{h})$} \\
\hline & \multicolumn{2}{|l|}{ equinox } & \multicolumn{2}{|l|}{ solstice } \\
\hline & $21^{\circ} \mathrm{N}$ & $21^{\circ} \mathrm{S}$ & $21^{\circ} \mathrm{N}$ & $21^{\circ} \mathrm{S}$ \\
\hline & $22.0 / 6.5$ & $24.8 / 6.2$ & $19.3 / 3.0$ & $17.5 / 3.7$ \\
\hline & $20.4 / 5.1$ & $22.8 / 5.0$ & $14.3 / 4.0$ & $15.1 / 4.8$ \\
\hline & $21.7 / 5.8$ & $23.2 / 5.8$ & $16.5 / 5.4$ & $13.6 / 6.1$ \\
\hline & $24.6 / 7.1$ & $26.5 / 6.8$ & $18.2 / 4.2$ & $15.2 / 4.7$ \\
\hline & $21.1 / 6.7$ & $22.6 / 6.4$ & $13.9 / 4.1$ & $12.0 / 4.6$ \\
\hline & \multicolumn{4}{|c|}{ Meridional wind perturbations $(\mathrm{m} / \mathrm{s} /$ local $\mathrm{h})$} \\
\hline & \multicolumn{2}{|l|}{ equinox } & \multicolumn{2}{|l|}{ solstice } \\
\hline & $21^{\circ} \mathrm{N}$ & $21^{\circ} \mathrm{S}$ & $21^{\circ} \mathrm{N}$ & $21^{\circ} \mathrm{S}$ \\
\hline $90^{\circ} \mathrm{E}$ & $32.5 / 1.3$ & $36.4 / 12.6$ & $27.8 / 20.6$ & $24.1 / 9.4$ \\
\hline $180^{\circ} \mathrm{E}$ & $29.0 / 23.8$ & $33.2 / 11.4$ & $21.4 / 21.8$ & $17.2 / 10.9$ \\
\hline $90^{\circ} \mathrm{W}$ & $32.1 / 0.7$ & $34.6 / 12.3$ & $21.6 / 23.2$ & $16.3 / 12.7$ \\
\hline $0^{\circ}$ & $37.8 / 1.9$ & $40.2 / 13.3$ & $25.3 / 21.7$ & $19.7 / 10.5$ \\
\hline Migrating only & $30.1 / 1.3$ & $33.2 / 12.8$ & $20.6 / 22.0$ & $16.3 / 11.0$ \\
\hline
\end{tabular}

variability of $J_{\theta}(\theta)$. The vertical distribution of the GSWM latent heating $J_{z}(z)$ is given by the empirical formula of Hong and Wang (1980):
$J_{z}(z)=A\left\{\exp \left[-\left(\frac{z-6.5}{5.39}\right)^{2}\right]-0.23 \exp \left(-\frac{z}{1.31}\right)\right\}$

We use the normalization constants given by Hong and Wang, so $A=5.34 \mathrm{~mW} / \mathrm{kg}$ for a rainfall rate of $1.0 \mathrm{~mm} /$ day. Figure 5 clearly illustrates that the migrating diurnal latent heating inferred from the cloud imagery contains a pronounced annual variation. Peak heating is located in the extratropical summer hemisphere, but the austral peaks extend nearly $25^{\circ}$ poleward of the boreal peaks. There is a fairly sharp transition from the summer to winter pattern which occurs during equinox.

Figure 6 illustrates the seasonal variability of the GSWM migrating diurnal response of northward winds at 12 LT to the monthly mean latent heat forcing. As expected, given the seasonal variability of the forcing illustrated in Fig. 5, the response is clearly most pronounced during January (top left). Meridional wind speeds peak in excess of $20 \mathrm{~m} / \mathrm{s}(15 \mathrm{~m} / \mathrm{s})$ near $20^{\circ} \mathrm{N}$ $\left(20^{\circ} \mathrm{S}\right)$ and $150 \mathrm{~km}$. Results for April (top right) and October (bottom right) are comparable, as is the forcing during equinox (Fig. 5). Tropospheric latent heating produces MLT diurnal wind variations of up to $10 \mathrm{~m} / \mathrm{s}$. 


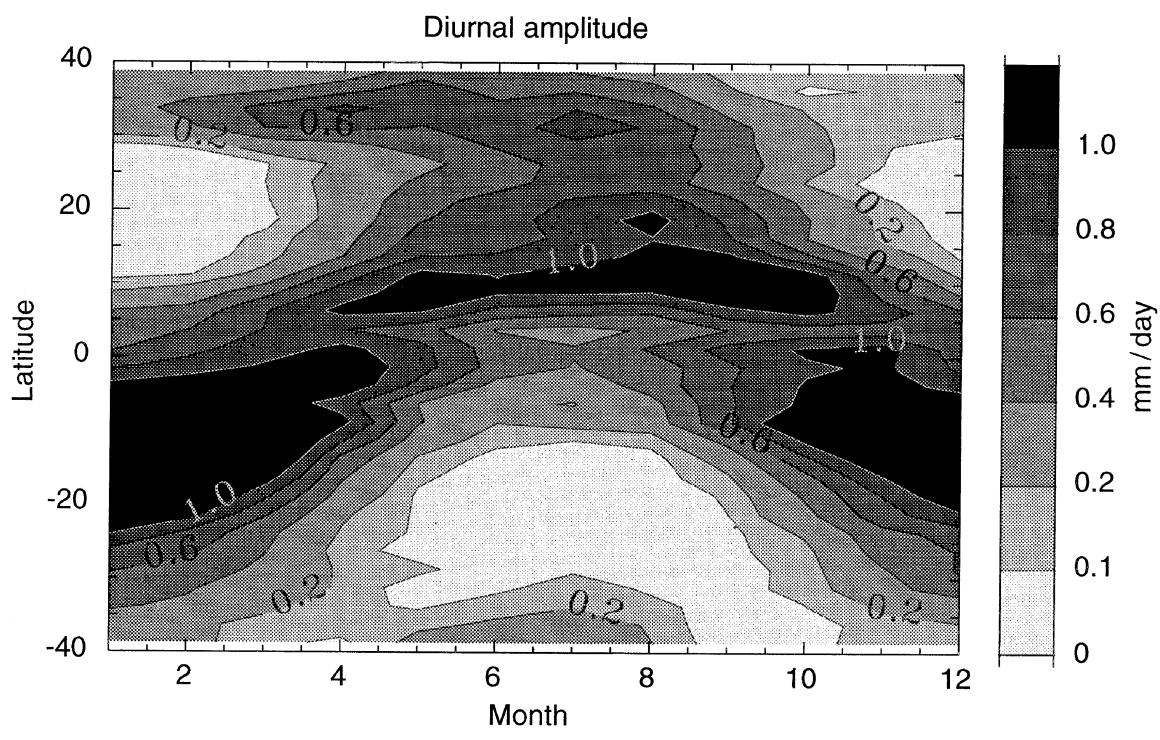

Fig. 5. Contours of the diurnal amplitude of effective rainfall rate ( $\mathrm{mm} /$ day) deduced from global cloud imagery data plotted versus month (number) of the year and latitude. These rates are used to specify the monthly variation of the latitude distribution of latent heating in GSWM

The response is comparatively negligible $(<5 \mathrm{~m} / \mathrm{s})$ during July (bottom left), however; given the latitudinal distribution of the source function (Fig. 5), this is expected.
The seasonal variability illustrated in Figs. 5 and 6 suggests that the inclusion of tropospheric latent heating will not address the GSWM underestimates of the diurnal tide as observed by HRDI and WINDII

GSWM diurnal northward wind $\left(\mathrm{ms}^{-1}\right)$ at $12 \mathrm{~h}$ local solar time Diagnostic results: tropospheric latent heat forcing after Forbes et al. [this issue]
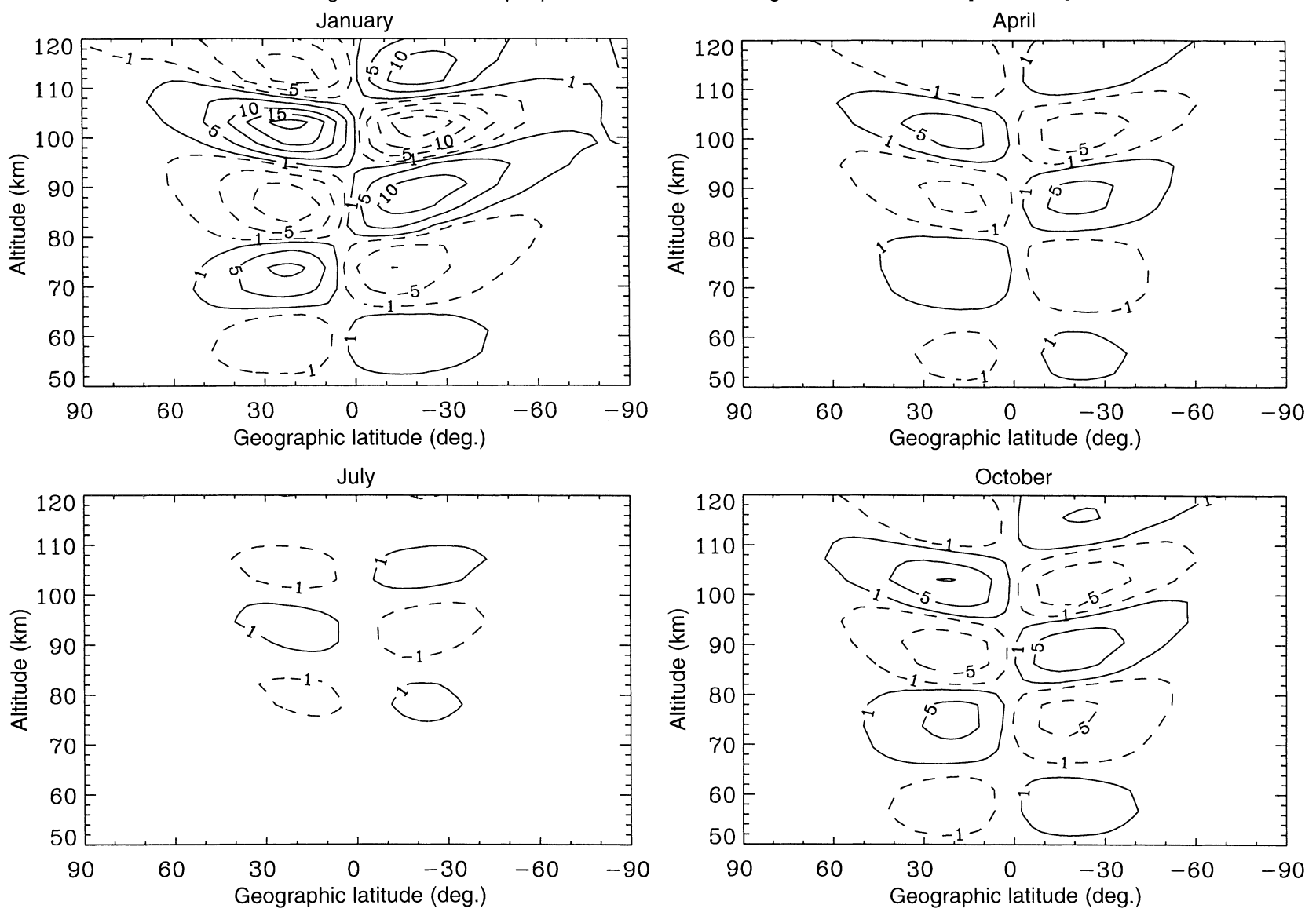

Fig. 6. The migrating GSWM diurnal northward wind response at 12 LST versus latitude and altitude (km) during January (upper left), April (upper right), July (bottom left), and October (bottom right) 


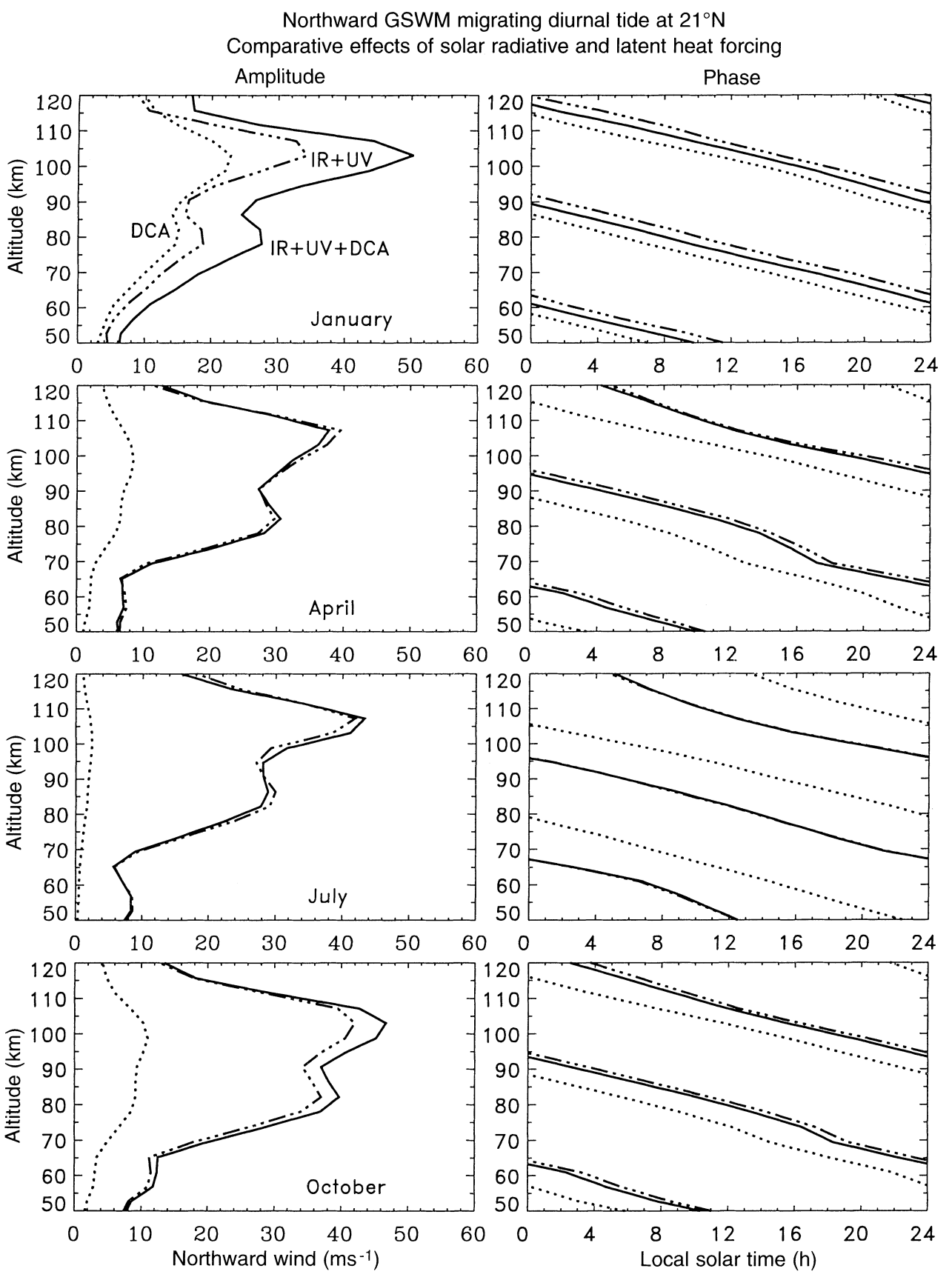

Fig. 7. Altitude profiles of migrating diurnal northward wind amplitude (left column) and phase (right column) at $21^{\circ} \mathrm{N}$ during January (top row), April (2nd row), July (3rd row), and October (bottom row) for tropospheric DCA (dotted curves), combined IR and UV (dot-dashed curves), and all three (solid curves) tidal forcing functions
(McLandress et al., 1994; Burrage et al., 1995). Nevertheless, Fig. 5 also illustrates the important effects and the profound seasonal variability of this migrating diurnal source. We further quantify its comparative importance in Fig. 7. Therein, we illustrate northward wind amplitudes (left column) and phases (right column) at $21^{\circ} \mathrm{N}$ resulting from our latent heating calculations (dotted curves) with the GSWM climatological results (dot-dashed curves) (Hagan et al., 1995a, b) and the GSWM response when all migrating sources are included (solid curves) for January (top row), April (second row), July (third row), and October (bottom row) conditions. Hagan (1996) discussed the comparative importance of the migrating tidal attributable to absorption of infrared (IR) and ultraviolet (UV) which comprise the climatological forcing. Figure 7 illustrates that the combination of the IR and UV sources produces MLT amplitudes that are 3-4 times larger than the response associated with cloudiness and rainfall or DCA during most of the year. However, the DCA response during January is about $60 \%$ as large as the UV and IR component. Further, because the phases are within about $2 \mathrm{~h}$ of each other, the net effect of combining the effects DCA with the other sources is to produce a peak meridional wind amplitude of about $50 \mathrm{~m} / \mathrm{s}$ at $21^{\circ} \mathrm{N}$ during January.

Figure 7 illustrates that the addition of migrating DCA forcing in no way improves the ability of GSWM to predict the observed seasonal variability of the diurnal tide. Rather, its inclusion serves further to 
strengthen the response during boreal winter, precisely when HRDI and WINDII are observing comparatively weak diurnal tidal signatures. We conclude that the numerical experiments discussed in this section support the suggestions put forth by Burrage et al. (1995) and Geller et al. (1997). Specifically, inadequacies in the current dissipative parameterization schemes are responsible for GSWM underestimates of diurnal tidal seasonal variability.

\section{Summary and conclusions}

We present additional numerical evidence that tropospheric latent heat release affects the diurnal tide in the MLT. First, nonmigrating latent heat forcing produces signatures which collectively modulate the migrating tide in the GSWM at MLT heights. These GSWM results capture the salient features of the MLT longitudinal diurnal tidal variability that are observed by WINDII onboard UARS and reported herein. Most notably, the nonmigrating components subtract from the migrating diurnal response at low latitudes in the Pacific longitude sector. We conclude that this feature of the nonmigrating MLT tidal response may partly explain the comparatively poor agreement between observations of the diurnal tide from measurements made with the partial reflection drift radar at Kauai, Hawaii and the migrating tidal results determined from HRDI and WINDII observations.

We also report on the observed seasonal variability of nonmigrating tidal effects and compare them with previous GSWM estimates (Hagan et al., 1997). Specifically, WINDII data analyses confirm that the nonmigrating tide affects the MLT most significantly during boreal winter.

Finally, we describe a series of GSWM calculations designed to explore the seasonal variability of the MLT response to the migrating component of tropospheric forcing attributable to latent heat release. Our results suggest that this source produces nonnegligible effects in the MLT, but that the source does not improve upon the weak seasonal variability of the diurnal tide in GSWM. Rather, our results provide additional support for the interpretation that GSWM dissipation schemes contain insufficient seasonal variability (Burrage et al., 1995; Geller et al., 1997).

Despite our inability to resolve the weak seasonal variability of the MLT response in GSWM by including the effects of latent heat release, we have demonstrated that this tidal source must be pursued to account fully for diurnal tidal variability in the MLT. In particular, ground-based determinations of the diurnal tide intrinsically contain nonmigrating signatures which are masked in the zonal mean tidal results obtained with standard satellite-data reduction techniques. Therefore, at least some portion of the discrepancy between the tidal climatologies deduced from these two different databases must be attributable to the nonmigrating diurnal tide.

In addition, the profound effects of the migrating diurnal component of the tropospheric latent heat source reported herein suggest that complementary nonmigrating calculations with the new heating rates may result in even larger longitudinal variability in GSWM MLT results. We intend to pursue these effects in a follow-on study. We also plan to use the 7-year cloud imagery database to investigate whether deep convective activity may be a source of interannual variability of the diurnal tide in the MLT. In conclusion, we suggest that additional observational evidence of non-migrating tidal effects will be invaluable to our increased understanding of the role of the nonmigrating tide in coupling the lower and upper atmosphere.

Acknowledgements. The authors thank $\mathrm{X}$. Zhang for preparing Fig. 5 and W. Ward for comments on an initial draft of this report. The National Center for Atmospheric Research (NCAR) is sponsored by NSF. The efforts of M. E. Hagan are supported by the NSF CEDAR program and NASA grant S-97239-E to NCAR. C. McLandress thanks the Institute of Space and Terrestrial Science for its continued support of scientific analysis of WINDII data. J. M. Forbes' contributions to this work were supported by NSF grant ATM-9415874.

\section{References}

Burrage, M. D., M. E. Hagan, W. R. Skinner, D. L. Wu, and P. B. Hays, Long-term variability in the solar diurnal tide observed by HRDI and simulated by the GSWM, Geophys. Res. Lett., 22, 2641-2644, 1995.

Burrage, M. D., W. R. Skinner, D. A. Gell, P. B. Hays, A. R. Marshall, D. A. Ortland, A. H. Manson, S. J. Franke, D. C. Fritts, P. Hoffman, C. McLandress, R. Niciejewski, F. J. Schmidlin, G. G. Shepherd, W. Singer, T. Tsuda, and R. A. Vincent, Validation of the mesosphere and lower thermosphere wind from the high-resolution doppler imager on UARS, $J$. Geophys. Res., 101, 10365-10 392, 1996.

Forbes, J. M., M. E. Hagan, X. Zhang, and K. Hamilton, Upperatmospheric tidal oscillations due to latent heat release in the tropical troposphere, Ann. Geophysicae, this issue, 1997.

Garcia, R. R., and S. Solomon, The effect of breaking gravity waves on the dynamics and chemical composition of the mesosphere and lower thermosphere, J. Geophys. Res., 90, 3850-3868, 1985.

Gault, W. A., et al., Validation of $\mathrm{O}(1 \mathrm{~S})$ wind measurements by WINDII: the Wind Imaging Interferometer on UARS, $J$. Geophys. Res., 101, 10 405-10 430, 1996.

Geller, M. A., Kattatov, B. V., V. A. Yudin, and M. E. Hagan, Modeling the diurnal tide with dissipation derived from UARS/ HRDI Measurements. Ann. Geophysicae, this issue, 1997.

Groves, G. V., Hough components of water vapor heating, $J$. Atmos. Terr. Phys., 44, 281-290, 1982.

Groves, G. V., A global reference atmosphere from 18 to $80 \mathrm{~km}$, AFGL report TR-85-0129, 1985.

Groves, G. V., Final scientific report, AFOSR report 84-0045, 1987.

Hagan, M. E., Comparative effects of migrating solar sources on tidal signatures in the middle and upper atmosphere, $J$. Geophys. Res., 101, 21 213-21 222, 1996.

Hagan, M. E., J. M. Forbes, and F. Vial, A numerical investigation of the propagation of the quasi-2-day wave into the lower thermosphere, J. Geophys. Res., 98, 23 193-23 205, 1993.

Hagan, M. E., J. M. Forbes, and F. Vial, On modeling migrating solar tides, Geophys. Res. Lett., 22, 893-896, 1995a.

Hagan, M. E., J. M. Forbes, and F. Vial, An updated model of migrating tides in the middle atmosphere: initial results and measurement comparisons, in Proc. Wind Observations in the Middle Atmosphere Workshop, CNES Headquarters, November 1994; Paris, France, Ed. 1995b. 
Hagan, M. E., J. L. Chang, and S. K. Avery, GWSM estimates of non-migrating tidal effects, J. Geophys. Res., in press, 1997.

Hays, P. B., V. J. Abreu, M. E. Dobbs, D. A. Grell, H. J. Grassl, and W. R. Skinner, The High Resolution Doppler Imager on the Upper Atmosphere Research Satellite, J. Geophys. Res., 98, 10713-10 723, 1993.

Hays, P. B., D. L. Wu, M. D. Burrage, D. A. Grell, H. J. Grassl, R. S. Lieberman, A. R. Marshall, Y. T. Morton, D. A. Ortland, and W. R. Skinner, Observations of the diurnal tide from space, $J$. Atmos. Sci., 51, 3077-3093, 1994.

Hedin, A. E., Extension of the MSIS thermosphere model into the middle and lower atmosphere, J. Geophys. Res., 96, 1159-1172, 1991.

Hong, S.-S., and P.-H. Wang, On the thermal excitation of atmospheric tides, Bull. Geophys., 19, 56-83, 1980.

Janowiak, J. E., P. A. Arkin, and M. Morrissey, An examination of the diurnal cycle in oceanic tropical rainfall using satellite and in situ data, Mon. Weather Rev., 122, 2296-2311, 1994.

Keating, G. M., M. C. Pitts, and C. Chen, Improved reference models for middle atmosphere ozone, Adv. Space Res., 10(6), 37-49, 1990.

Khattatov, B. V., M. A. Geller, V. A. Yudin, P. B. Hays, W. R. Skinner, Burrage, M. D., S. J. Franke, D. C. Fritts, J. R. Isler, A. H. Manson, C. E. Meek, R. McMurray, W. Singer, P. Hoffman, and R. A. Vincent, Dynamics of the mesosphere and lower thermosphere as seen by MF radars and the highresolution Doppler imager/UARS, J. Geophys. Res., 101, 10 393-10 404, 1996.

Khattatov, B. V., M. A. Geller, V. A. Yudin, and P. B. Hays, Diurnal migrating tide as seen by HRDI/UARS, 2. Monthly mean global zonal and vertical velocities, pressure, temperature, and inferred dissipation, J. Geophys. Res., 102, 4423-4435, 1997.

Lindzen, R. S., and H. L. Kuo, A reliable method for the numerical integration of a large class of ordinary and partial differential equations, Mon. Weather Rev., 97, 732-734, 1969.
McLandress, C., and W. E. Ward, Tidal/gravity wave interactions and their influence on the large-scale dynamics of the middle atmosphere: model results, J. Geophys. Res., 99, 8139-8155, 1994.

McLandress, C., Y. Rochon, G. G. Shepherd, B. H. Solheim, G. Thullier, and F. Vial, The meridional component of the thermospheric tide observed by WINDII on UARS, Geophys. Res. Lett., 21, 2417-2420, 1994.

McLandress, C., G. G. Shepherd, and B. H. Solheim, Satellite observations of thermospheric tides: results from the wind imaging interferometer on UARS, J. Geophys. Res., 101, 40934114, 1996a.

McLandress, C., G. G. Shepherd, B. H. Solheim, M. D. Burrage, P. B. Hays, and W. R. Skinner, Combined mesosphere/ thermosphere winds using WINDII and HRDI data from the Upper Atmosphere Research Satellite. J. Geophys. Res., 101, 10441-10453, 1996b.

Miyahara, S., and J. M. Forbes, Interaction between gravity waves and the diurnal tide in the mesosphere and lower thermosphere, J. Meteorol. Soc. Japan, 69, 523-532, 1991.

Portnyagin, Yu. I., and T. V. Solov'eva, An empirical model of the meridional wind in the mesopause-lower thermosphere, Part 1., a mean monthly empirical model, Russian J. Met. Hydr., 10, 2835, 1992a.

Portnyagin, Yu., I., and T. V. Solorv'eva, An empirical model of the meridional wind in the mesopause/lower thermosphere, Part 2., height-latitude features of basic components of meridional wind seasonal variations, Russian J. Met. Hydr., 11, 29-36, 1992 b.

Shephered, G. G., et al. WINDII, the Wind Imaging Interferometer on the Upper Atmosphere Research Satellite, J. Geophys. Res., 98, 10725-10750, 1993.

Strobel, D. F., Parameterization of the atmospheric heating rate from 15 to $120 \mathrm{Km}$ due to $\mathrm{O}_{2}$ and $\mathrm{O}_{3}$ absorption of solar radiation, J. Geophys. Res., 83, 6225-6230, 1978.

Williams, C. R., and S. K. Avery, Non-migrating diurnal tides forced by deep convective clouds J. Geophys. Res., 101, 40794091, 1996. 